\title{
História e Literatura: O Folheto de Cordel em Territórios de Fronteiras ${ }^{\mathrm{I}}$
}

\section{Kalhil Gibran Melo de Lucena ${ }^{\mathrm{II}}$}

Resumo: Os folhetos de versos ou de cordel se constituem como uma produção literária que pode ser utilizada como uma importante fonte de pesquisa histórica. É possível usar os escritos dos poetas da arte de versejar com o intuito de analisar a construção, as transformações e as permanências peculiares da sociedade brasileira. $\mathrm{O}$ objetivo desse artigo é promover um diálogo entre História e Literatura, apresentando o cordel como um produto cultural que pode transitar entre as fronteiras dessas duas áreas do conhecimento. Em suma, compreendemos que a literatura de folhetos relata os acontecimentos políticos, econômicos, religiosos e culturais de um determinado período e tessitura social, configurando-se como uma das possibilidades de memória, documento e registro da história da sociedade brasileira.

Palavras-chave: História Cultural; Literatura; Arte de Versejar.

\section{History and Literature: The Cordel in Border Territories}

Abstract: The written verses or cordel literature as they constitute a literary output that can be used as an important source of historical research. You can use the writings of poets the art of rhyme in order to analyze the construction, changes and continuities of the peculiar Brazilian society. The aim of this paper is to promote a dialogue between history and literature, presenting the string as a cultural product that can move between the boundaries of these two areas of knowledge. In short, we understand that literature booklet recounts the political, economic, religious and cultural events in a specified period and social fabric, configuring itself as one of the possibilities of memory, document and record the history of brazilian society.

Keywords: Cultural History; Literature; Art of rhyme.

Artigo recebido em 18/02/2015 e aprovado em 01/03/2015. 


\section{KALHIL GIBRAN MELO DE LUCENA}

\section{Introdução}

Os folhetos de cordel compõem o complexo repertório social e cultural brasileiro. É possível concebê-los como um discurso da realidade, como uma prática cultural que pode contribuir para a elaboração de uma série de representações de um período histórico. Nesse sentido, os poetas de cordel produzem em meio as suas práticas, versos rimados que tratam de uma realidade e de um cotidiano, que representam vidas, alegrias, sofrimentos, amor, ódio, riso, fé, cidadania, cultura, política e história.

Fazendo uso de Michel de Certeau ${ }^{\text {III }}$ pode-se visualizar nos cordéis particularidades que fabricam as pluralidades de uma cultura, eles são artes de fazer, táticas de uma produção popular cotidiana que produz uma antidisciplina em relação a uma ordem social hegemônica e a um sistema cultural instituído. Eles além de testemunharem um passado, apresentam-se com uma forma de ler e ouvir diferente de um texto convencional. Possuem um poder de atração que se expressa a partir das rimas, da musicalidade, da liberdade de pensamento e dos gracejos de seus versos.

Destarte, estruturamos esse texto na premissa de que as parcerias e diálogos da História devem ir para além de fronteiras fixas que impeçam a hibridização do conhecimento. Dessa forma, tivemos aqui a intenção de promover um diálogo entre História e Literatura, compreendendo a arte de versejar como uma forma de produção intelectual, que pode ser utilizada como fonte histórica e como uma forma de literatura. Assim, concebemo-las como discursos sobre o mundo, entendendo que é preciso diluir as dualidades e oposições como, verdade versus ficção, realidade versus imaginação, ciência versus arte.

Entretanto, ao pensar nas fronteiras da História com relação às outras áreas do conhecimento, nos interessa focar nos intercâmbios de saberes, nas parcerias que a pesquisa histórica pode estabelecer com as outras ciências humanas e, nesse sentido, as proposições teóricas da História Cultural são muito relevantes para nos auxiliar.

\footnotetext{
"Com o advento da História Cultural, novos parceiros surgem, em função das questões formuladas, das temáticas e objetos novos, das também renovadas fontes com as quais o historiador passa a trabalhar. Mas agora pode-se mesmo falar de um novo enfoque, que joga a História nas fronteiras do conhecimento". IV
}

Desta maneira, é a partir dos diálogos fronteiriços, alicerçados nas influências recíprocas, como os permeados entre a História e a Literatura, que esse artigo vem se localizar. No entanto, compreendemos que o conhecimento histórico deve ser produzido sem demarcações que o singularizem. E nesse cenário, Sandra Pesavento, ao intuir sobre essa questão, nos afirma que "a situação de fronteira se dá também na pluri ou mesmo na transdisciplinaridade que se revela na escolha de temas e objetos ${ }^{\mathrm{V}}$. Portanto, é pertinente ressaltar que os folhetos de cordel podem se apresentar como uma ferramenta dialógica relevante entre essas duas áreas do conhecimento.

Finalmente, é possível afirmar que as rimas dos folhetos de versos produzem deslocamentos de sentidos, e a partir do riso e da ironia podem se apresentar como uma maneira bem peculiar de representação das questões socioculturais e políticas da sociedade brasileira. Os poetas da arte de versejar não são sujeitos sociais que trazem explicações definitivas de um cenário sociocultural, mas são aqueles que narram, que contam grandes e pequenos acontecimentos numa narrativa versificada aberta a várias interpretações e construída por discursos heterogêneos. E mesmo não sendo como um historiador que se apega a métodos, teorias e hipóteses, o poeta é um narrador que fabrica histórias que abrem a possibilidade de interpretações dos acontecimentos pretéritos para uma pesquisa/produção historiográfica. 


\title{
2. Folhetos de feira, Literatura e História
}

\author{
"Como nós queremos estudar o cordel como literatura, é pelos temas \\ literários, independentemente do gênero, que o cordel se impõe". vl
}

As formas de leitura dos grupos culturais na contemporaneidade são bem divulgadas e disseminadas, como: livros, e-books, jornais, revistas, manuais didáticos. Nesse cenário, a literatura de versos rimados vem se apresentando como uma produção pouco consumida e consultada. É possível escutar pessoas dizendo que adoram ler "literatura de cordel nordestina", mas não possuem sequer meia dezena deles em seus guardados pessoais. Então, afinal de contas, por que sua riqueza cultural, literária e histórica não é bem difundida na sociedade brasileira (como nas escolas e nas universidades)? Qual o motivo desses poemas rimados serem considerados como uma produção literária periférica, que remete a idéia de um invólucro vazio, fixada numa tradição folclórica? Por que os folhetos de versos são tidos como literatura popular, destituída de valor intelectual? Na realidade não intencionamos trazer respostas prontas e acabadas para tais questões, mas a intenção é refleti-las.

Ademais, a literatura de cordel é espetacularizada como um produto cultural folclórico do Nordeste. Intencionamos desnaturalizar essa questão e considerar tais folhetos como uma produção intelectual não acadêmica, porém, uma forma textual digna de não ser considerada como um tipo de Literatura de segunda categoria. Portanto, pretendemos visualizar os folhetos como documento histórico e como produção literária, concebendo-os como narrativas que representam a vivência política e sociocultural de cada poeta.

Entretanto, condescendemos com a pesquisadora Ana Maria Galvão quando define a arte de versejar como um tipo de literatura.

\section{(...) A literatura de folhetos tornou-se um impresso de larga circulação (...) o poeta recorre a uma enciclopédia que, ao mesmo tempo, enraíza o leitor em sua vida diária e o transporta para outros espaços e tempos. De modo geral, os textos pressupõem um leitor pouco interessado em conhecer os detalhes ou o desfecho de uma ou outra narrativa, é ávido sobretudo de, através da experiência literária, reforçar determinados valores $(\ldots)^{\mathrm{VII}}$}

Os folhetos de versos são, antes de tudo, uma parte das vozes criadas e transmitidas por poetas que cumprem de certa forma uma função literária e histórica. Afinal de contas, a produção de versos rimados no universo da literatura de folhetos não deve ser considerada como uma produção espontânea e ingênua.

Aderaldo Luciano, doutor em Ciência da Literatura, esclarece-nos de forma habilidosa que nos últimos anos muitos pesquisadores não se preocuparam em ter um cuidado apurado em seus estudos sobre os folhetos de cordel, (re)produzindo ideologias negativas, pejorativas e preconceituosas. Passando a simplesmente formular de forma engessada afirmações que os definem como subprodutos de uma tradição oral, de origem lusitana/ibérica, ou ainda como popular no sentido artesanato/folclórico, o popular como algo exótico e sem valor intelectual. ${ }^{\text {VIII }}$

É injustiça os manuais de literatura brasileira não apresentarem Leandro Gomes de Barros aos nossos estudantes de Letras, além de ignorar por completo sua vasta obra. É de se lamentar que as antologias de literatura brasileira fechem suas portas a João Martins de Ataíde por entender que o cordel de sua lavra não é poesia e, se poesia, popular (...) a academia fechou as suas portas. Apesar dos estudos realizados dentro dos muros dos castelos acadêmicos, o cordel continuou na periferia literária. ${ }^{\mathrm{IX}}$ 


\section{KALHIL GIBRAN MELO DE LUCENA}

Entretanto, concordamos com o professor Aderaldo Luciano quando defende "o cordel como produção literária, como literatura ${ }^{\mathrm{X}}$,, os folhetos para ele devem ser concebidos como poesia, ou seja, uma forma poética que compreende o narrativo, o dramático, o lírico.

A pesquisadora Bruna Paiva de Lucena também corrobora com as ideias de Aderaldo Luciano, e dessa forma ela explana que o campo literário brasileiro para afirmar a superioridade de poéticas eruditas, segrega e deslegitima alguns tipos de produções literárias, como é o caso dos folhetos de versos, que "por meio da desvalorização de seus atributos constitutivos - rima, ritmo, repetição, improvisação, memorização, entre outros - são tidos como recursos pobres e menores ${ }^{\mathrm{XI}}$,

Bruna Lucena afirma-nos ainda que quando a literatura de folhetos é cunhada como cultura popular ou como de uma tradição oral ela está sendo delimitada por valores conservadores e excludentes. Para essa pesquisadora isso é típico da literatura oficial e hegemônica, que ao longo da historiografia literária brasileira deslegitimou e silenciou muitas outras narrativas literárias. XII

Assim como Aderaldo Luciano, ela também faz críticas ao cordel enquanto uma poética da oralidade, porque isso contribui para uma marginalização dos folhetos no campo literário, ou seja, posta à margem por um campo e um sistema literários que a desprezam e que só legitimam as produções estabelecidas pelos cânones oficiais da historiografia literária.

Construídos, em sua maioria, por intelectuais e suas instituições, os cânones historiográficos carregam em sua constituição uma "vontade de verdade e poder", em termos foucaultianos, que se estabelece por meio de discursos sobre o que e (e deve ser) parte constitutiva de uma determinada historiografia. ${ }^{\text {XIII }}$

Por conseguinte, a denominação popular e a tradição oral impostas aos folhetos disseminam uma série de preconceitos. "Por ser de outra tradição - da oralidade - o cordel é muitas vezes estudado como gênero menor, folclore, e expressão de um povo ${ }^{\text {XIV }}$ ". É dessa forma, que para Bruna Lucena, os poemas dos folhetos de versos são tidos preconceituosamente como pseudoliteratura - "pela origem de seus autores e pela tradição literária a que pertencem - no caso a oral" ${ }^{\mathrm{XV}}$. Assim, quando se denomina o folheto de verso rimado como um produto fixado essencialmente numa tradição oral, exerce-se um "preconceito epistemológico que a cultura da escritura instituiu XVI",

O poeta de folhetos rimados é marginalizado enquanto produtor literário, porque a literatura oficial possui um teor autoritário e quem não se enquadrar em uma dada oficialidade produz apenas cultura popular, periférica, menor. Nesse cenário, quem se afasta das experiências artísticas e culturais oficiais é caracterizado "como sinônimo de decadência cultural e barbárie ${ }^{\mathrm{XVII}}$ ", Assim, é a tradição literária escrita e hegemônica que exerce o papel de proprietária exclusiva do poder da palavra.

Com a substituição da oralidade como fonte e local de armazenamento do saber pela cultura escrita, comeca-se a difundir entre as classes pobres e populares, detentoras apenas do saber oral, o sentimento de incultura quanto a sua produção artística e cultural que, em contrapartida a cultura erudita - de intelectuais -, passa a significar apenas o atrasado, o vulgar e o comum. ${ }^{\text {XVIII }}$

Mediante esses parâmetros teóricos é possível perceber que a poesia de folhetos, por ser visualizada como algo menor, inferior a literatura de tradição literária escrita, "carrega em si uma série de características: ser de autoria de pobres que vêem de forma ingênua o mundo, ocupam profissões subalternas, possuem pouca ou nenhuma escolarização, escrevem/cantam por dom e não por arte ${ }^{\mathrm{XIX}}$ ". Portanto, quando se adentra no universo da literatura de folhetos, adicionados a exclusão dela aos estudos literários, "tem-se a marginalização de seus produtores, de seu suporte e de seu público ${ }^{\mathrm{XX}}$. 


\section{KALHIL GIBRAN MELO DE LUCENA}

É importante ressaltar ainda que a palavra cordel ajudou a fabricar um mito folclórico, ou seja, um discurso inventado para reforçar uma identidade regional nordestina, que remete a uma realidade cultural portuguesa.

Desse modo, cordel é um conceito criado pelos folcloristas, por uma elite intelectual, e assimilado pelos cantadores repentistas e folheteiros, como algo que poderia normalmente se remeter a uma origem lusitana, uma forma de atribuir uma gênese portuguesa a esse tipo de produção cultural do Brasil. Entretanto, pelo que constatamos na documentação que utilizamos em nossa dissertação de mestrado e ainda pelo que afirma o historiador Durval Muniz $^{\mathrm{XXI}}$, utilizar o termo cordel poderia reverberar como algo anacrônico, ou seja, deslocado de sentido em relação ao recorte temporal da Primeira República, por exemplo. Assim, na produção de nossa dissertação, nos referimos aos folhetos produzidos e veiculados pelos poetas da arte de versejar nesse período como literatura de folhetos, livretos, folhetos de versos ou de feira, e não como cordel.

Nessa perspectiva, é possível perceber que assim como a cultura nordestina é um acontecimento recente, muitas das práticas e conceitos que esta maneja como: literatura de cordel, peleja, autor proprietário, editor proprietário, cordelista, nada têm de tradicionais, são invenções do mundo moderno e possíveis por causa dele, são fruto da emergência de novas práticas culturais propiciadas pelo meio urbano. ${ }^{\text {XXII }}$

Entretanto, desconsiderando os que determinam a arte de versejar em rimas como subliteratura e colocando-a em uma situação de exclusão, promoveremos um diálogo entre História e Literatura, pensando os folhetos de feira como um tipo de Literatura.

Há alguns anos os textos literários passaram a ser visualizados pelos historiadores como materiais propícios a múltiplas leituras, especialmente por sua riqueza de significados para o entendimento do universo cultural, dos valores sociais e das experiências subjetivas da sociedade humana no tempo. ${ }^{\mathrm{XIII}}$

Ferreira ${ }^{\text {XIV }}$ explica-nos que desde a década de 1970, as novas gerações de historiadores franceses aumentaram as possibilidades de problemas, objetos e abordagens da disciplina histórica. Eles também estimularam a pesquisa de novos documentos, como: escritos, sonoros e visuais. A ampliação do repertório das fontes históricas e as transformações do próprio conceito de fonte inseriram-se no crescente movimento de renovação da historiografia no século XX.

Diante dessa perspectiva, de utilização de novas fontes de pesquisa, a História assume uma postura interdisciplinar que passa a valorizar não apenas os documentos políticos oficiais, mas, passa a abrir também espaço para a investigação dos textos literários, como a literatura de folhetos. Ana Maria Galvão ${ }^{X X V}$ elucida que no caso dos folhetos de versos o que se destaca não é a reconstituição de um fato em si, ou ainda, de rimas que expressem uma verdade absoluta, mas de um formato literário mergulhado nas subjetividades tanto dos poetas quanto dos leitores.

O que parece importar para o suposto leitor é, pois, menos a "atualidade" ou a informação objetiva sobre o fato/a notícia, e mais os valores universais rememorados pela história, nos quais ele crê e deles se alimenta cotidianamente (...) levando-os a se sentir à vontade com a estrutura e o teor das histórias. ${ }^{\mathrm{XVI}}$

Assim, é possível afirmar que os folhetos de feira, enquanto produção literária, se apresentam como uma fonte de pesquisa histórica interessante porque seus "poemas parecem reforçar certos valores, ideias e modos de pensamento"XXVII, que vão além de um documento histórico/político oficial, dessa forma eles se inserem nesse cenário de ampliação das fontes da História.

$\mathrm{Na}$ segunda metade do século XX, a partir dos estudos lingüísticos, uma nova conceituação começou a ser adotada para caracterizar a especificidade da criação literária. 
Passou-se a enfatizar não tanto o conteúdo das obras mais o modo como a literatura se realiza, ou seja, as diferentes linguagens utilizadas para a criação artística. Compreendida dessa forma, a literatura passou a ser entendida não como algo que documenta o real, nem como um texto que constitui representação semelhante aos discursos científico, filosófico ou político. XXVIII Nesse sentido, o texto literário não pode ser concebido pelo historiador como uma linguagem que se assemelha na íntegra a um acontecimento pretérito ou que equivale a um espelho do presente.

É muito comum se ouvir definições simplistas e cristalizadas de que Literatura é um discurso que trata do imaginário, enquanto que a História é uma narrativa dos fatos verídicos das diferentes épocas. Contudo, para Sandra Pesavento ${ }^{X I X}$ História e Literatura podem se aproximar sem se confundir. Elas correspondem a narrativas explicativas do real que se renovam no tempo e no espaço. Esse diálogo promove um campo de pesquisa que passou a se desenvolver no Brasil a partir dos anos 90, se revelando hoje como uma das temáticas relevantes em termos de pesquisas e trabalhos acadêmicos.

A aproximação destas duas formas de conhecimento configura-se como discursos sobre o mundo, e nesse cenário é preciso assumir posturas epistemológicas que diluam fronteiras e relativizem as dualidades e oposições como, verdade versus ficção, realidade versus imaginação, ciência versus arte. Consequentemente, Literatura e História são narrativas que tem o real como referente, para confirmá-lo ou negá-lo, construindo sobre ele toda uma outra versão, ou ainda para ultrapassá-lo. Como narrativas, são representações que se referem à vida e que a explicam. $\mathrm{XXX}$

A história é sempre construção de uma experiência, que reconstrói uma temporalidade e a transpõe em narrativa. Portanto, os historiadores são mediadores de temporalidades, passado e presente estão constantemente se conectando, a partir da leitura das fontes históricas e da escrita historiográfica. Diferentemente dos que escrevem Literatura, o historiador não cria personagens nem fatos. Mas, os "descobre", fazendo-os sair da sua invisibilidade.

Diante dessa perspectiva, Sandra Pesavento alerta-nos que o historiador é um narrador, e assim possui tarefas narrativas a cumprir: ele reúne os dados, seleciona, promove conexões e cruzamentos entre eles, elabora uma trama, apresenta possíveis soluções para interpretar um acontecimento pretérito, e se vale das estratégias de retórica para convencer o leitor a partir de uma escrita que ofereça uma versão que se aproxime de uma realidade acontecida. Portanto, os historiadores elaboram versões plausíveis, possíveis, aproximadas, daquilo que teria se passado um dia. Eles atingem a verossimilhança, não a veracidade. ${ }^{\text {XXI }}$

A escrita da História é uma representação de um passado. Ela constrói uma possibilidade de acontecimento, num tempo onde não esteve presente e que é reconfigurado pela narrativa. Nesta medida, a narrativa histórica mobiliza os recursos da imaginação, dando a ver e ler uma realidade passada que só pode chegar até o leitor pelo esforço do pensamento $^{\mathrm{XXXII}}$. Nesse sentido, as obras ficcionais produzidas pelo universo literário apresentam-se como uma possibilidade de fonte documental para construção do conhecimento histórico, haja vista a Literatura ser uma área do conhecimento humano que promove certa leitura e interpretação da sociedade.

Nesse cenário, é possível constatar nas produções textuais dos poetas dos folhetos de cordel uma certa leitura da sociedade de seu tempo, como por exemplo, ao interpretarem alguns fragmentos cotidianos da jovem República. Nos versos a seguir do folheto intitulado $A$ Discussão de Rufino Fonseca com Antonio Eugenio ${ }^{\text {XXIII }}$ podemos visualizar tal questão. Tal folheto é um desafio/peleja entre cantadores fictícios que duelam com as armas dos versos e do som da viola. Portanto, o velho Rufino Fonseca, o personagem imaginário que defende os tempos antigos, finda nos oferecendo pistas para entender um pouco de um presente republicano de intensas transformações nos hábitos e costumes socioculturais dos brasileiros. 


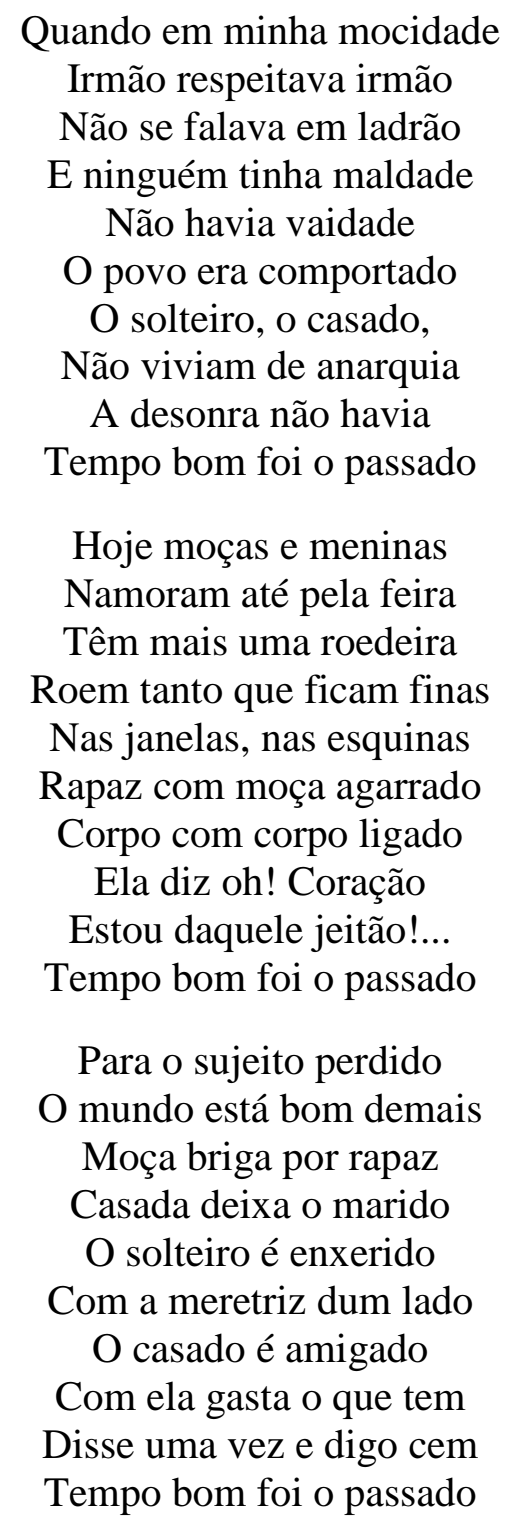

"Ao poeta caberia recolher no cotidiano, isto é, nos fatos e nos feitos, o material ou a matéria-prima que lhe servirá de fonte para a fabulação e, assim, constituir a narrativa dos acontecimentos". XXXIV Contudo, é em determinadas condições de espaço, tempo, cultura e relações sociais que o poeta cria seus mundos de sonhos, utopias ou desejos, explorando ou inventando formas de linguagem. ${ }^{\mathrm{XXV}}$ Nos folhetos de versos, "as impressões transmitidas ao leitor pelo poeta e a receptividade desses textos consolidam uma visão de mundo que passa a ser abonada como verdadeira". XXXVI

O historiador deve estar atento a diversidade das formas literárias no tempo e as circunstâncias em que se constituíram, perpetuaram ou mudaram suas convenções. Muito se debateu, e ainda se debate, acerca do valor estético, social ou lingüístico da literatura. Entretanto, o objetivo do historiador precisa ser o de procurar compreender como tais avaliações são constituídas no interior das sociedades, de que maneira se formam e disseminam os gostos literários, como repercutem no coletivo e permanecem ou não historicamente. Devem interessar a pesquisa histórica todos os tipos de textos literários, na medida em que sejam vias de acesso a compreensão dos contextos sociais e culturais pertinentes à problemática do estudo. XXXVII 


\section{KALHIL GIBRAN MELO DE LUCENA}

Sandra Pesavento ${ }^{\text {XXXVIII }}$ elucida que a História é a narrativa organizada dos fatos acontecidos, essa área do conhecimento humano se baseia mais em versões e possibilidades do que certezas. É muita pretensão achar que é possível atingir um passado na sua integridade. Assim, o fato histórico é, em si, também criação pelo historiador, mas na base de documentos "reais" que falam daquilo que teria acontecido.

O historiador está preso às fontes e à condição de que tudo tenha acontecido. Ele atribui significado as fontes. Há que considerar ainda que estas fontes não são o acontecido, mas rastros para chegar a este. As fontes históricas, como a literatura de folhetos, são representações acerca do que se passou, sobre o real. Assim, os traços que chegam do passado suportam esta condição dupla: por um lado, são restos, marcas de historicidade; por outro, são representações de algo que teve lugar no tempo. XXXIX

Destarte, Ferreira ${ }^{\mathrm{XL}}$ nos instrui que o historiador não deve se deixar seduzir por rótulos ou moldes literários, ele não deve se apegar a uma rigidez classificatória das obras literárias, como: classicismo, romantismo, realismo, modernismo. Assim, o historiador precisa ter cuidado com os marcos periodizadores estanques dos movimentos literários na história da literatura, pois esses podem subordinar seus significados históricos a uma visão unilateral. Consequentemente, outra preocupação pertinente deve ser a de estar atento aos gêneros literários, pois estão intimamente relacionados às condições sociais e históricas que determinam a formação do público leitor com seus gostos e sensibilidades (a epopéia, o conto, a novela, a ficção romanesca, a tragédia e a comédia). Contudo, as representações literárias constituem sempre um universo ficcional, por mais verossímil que sejam. O papel do historiador deve ser o de contextualizar a obra literária e aproximá-la dos múltiplos significados da realidade histórica.

Corolariamente, é de fundamental importância valorizar os diversos intercâmbios entre a literatura e a história, e nessa perspectiva cabe ao historiador compreender e explicar como tais permutas ocorrem em determinados contextos sociais e culturais. Nestes se incluem os meios de produção e difusão da cultura e do saber, bem como suas instituições reguladoras, que devem ser concebidos em permanente mudança. XLI

Sandra Pesavento ${ }^{\text {XLII }}$ afirma-nos que o historiador tem o mundo à sua disposição. Tudo para ele pode se converter em fonte, basta que se tenha um tema e um questionamento, alicerçado a partir de conceitos, que problematizem este tema e o construam como objeto. Partindo desse pressuposto o historiador poderá enxergar, descobrir, coletar documentos e indícios para a decifração de um problema. E assim, caberá a ele, a partir de tais elementos, inventar o passado. Todavia, a liberdade ficcional do historiador deve ter limites, porque ela está condicionada ao seu ofício, ou seja, se empenhar em atingir uma verdade possível, aproximada do real tanto quanto lhe for permitido.

É preciso reconhecer a presença de traços literários na escrita da História, porém, não se deve deixar de lado as operações específicas que a tipificam como disciplina: construção e tratamento dos dados, produção de hipóteses, crítica e verificação de resultados, validação da adequação entre o discurso do conhecimento e seu objeto. XLIII

A literatura pode ser uma fonte privilegiada para a história, porque dará ao historiador acesso especial ao imaginário, permitindo-lhe enxergar imagens sensíveis do mundo, traços e pistas que outras fontes não lhe dariam. A literatura é narrativa que, de modo ancestral, pelo mito, pela poesia ou pela prosa romanesca fala do mundo de forma indireta, metafórica e alegórica. Por vezes, a coerência de sentido que o texto literário apresenta é o suporte necessário para que o olhar do historiador se oriente para outras tantas fontes e consiga enxergar aquilo que ainda não havia conseguido visualizar. A literatura cumpre, assim, um efeito multiplicador de possibilidades de leitura. Ela é uma possibilidade de conhecimento do mundo. XLIV 


\section{KALHIL GIBRAN MELO DE LUCENA}

Antonio Celso Ferreira ${ }^{\mathrm{XLV}}$ esclarece-nos que a pesquisa histórica tem contribuído para a compreensão dos modos como a Literatura foi concebida, particularizada em relação a outras expressões orais ou escritas, transmitida, lida, compartilhada ou apropriada pelos diferentes grupos sociais das diversas épocas e sociedades. E, sobretudo, para o entendimento dos distintos papéis que, ao longo do tempo, ela desempenhou na existência dos seres humanos, em suas várias dimensões sociais ou subjetivas.

Para se interpretar o texto literário é essencial entender as particularidades dessa modalidade de expressão escrita, seja em relação à própria narrativa histórica seja na comparação a outros tipos de textos/fontes. Desse modo, é preciso, antes de tudo, não negligenciar os laços, atados ou soltos, entre a narrativa histórica e a narrativa literária. ${ }^{\mathrm{XLVI}}$

Sandra Pesavento ${ }^{\mathrm{XLVII}}$ nos diz que a verdade da ficção literária não está em revelar a existência real de personagens e fatos narrados, mas em possibilitar a leitura das questões em jogo numa temporalidade dada. Para o historiador que se volta para a literatura o que conta na leitura do texto não é o seu valor de documento, testemunho de verdade ou autenticidade do fato, mas o seu valor de problema. O texto literário revela e insinua as verdades da representação ou do simbólico através de fatos criados pela ficção. Assim, o texto literário é expressão ou sintoma de formas de pensar e agir. Ele não se apresenta como uma realidade acontecida em sua essência, mas como possibilidade, como postura de comportamento e sensibilidade, dotada de credibilidade e significância.

Deve-se pensar a literatura na relação com a história como um inegável e recorrente testemunho de seu tempo. E isso poderá proporcionar uma abertura dos campos de pesquisa para a utilização de novas fontes e objetos, entre as quais se encontra o texto literário.

O historiador Antonio Celso Ferreira ${ }^{\text {XLVIII }}$ nos diz que é muito comum que alguns pesquisadores iniciantes se questionem acerca de quais métodos específicos devem ser utilizados para uma devida abordagem da fonte literária. Na verdade, a historiografia não dispõe de metodologia, teoria e conceitos particulares ou unívocos para tal. O método de trabalho do pesquisador dependerá da problemática que o leva à investigação. Assim, é necessário delimitar com clareza o problema a ser estudado, e saber problematizar o porquê das fontes literárias serem canais promissores para a busca de respostas. É preciso, ainda, estar atento aos ambientes socioculturais do período analisado para se evitar o tratamento anacrônico da fonte.

Finalmente, os textos literários, como a literatura de folhetos, se constituem como uma fonte fecunda dos desejos que, inundando a materialidade das coisas, também constituem a História. Assim, os versos rimados de um folheto ou de um romance podem se configurar como uma preciosa via de acesso à História em seus dados de realidade e suas projeções subjetivas. XLIX

\section{Considerações Finais}

Pensamos a História como multiplicidade, pluralidade, hibridização. Ela é a área do conhecimento que conecta tempos e espaços a partir de constantes diálogos, das representações e de interpretações. A labuta historiográfica é produção intelectual, tecitura de saberes. "Tecer, como narrar, é relacionar" ${ }^{\mathrm{L}}$ ". Assim, o historiador realiza interposições, tendo "como principal instrumento a narrativa, a linguagem, que é o recurso fundamental de mediação, de mistura, de relação do homem com o mundo ${ }^{\text {LI" }}$.

Escrever História é também mediar temporalidades, exercer a atividade de tradução entre naturezas, sociedades e culturas de tempos distintos. Colocados nesta terceira margem da temporalidade, que é o presente, o historiador tem a tarefa de construir 


\section{KALHIL GIBRAN MELO DE LUCENA}

com sua narrativa uma canoa que possa mediar, fazer se tocar as margens do passado e do futuro. ${ }^{\text {LII }}$

A História é conflituosa, instável, inconstante. Ela se constrói num terreno de alianças, oposições e enfrentamentos. É nesse ambiente imprevisível que o historiador tece seus fios, a partir da escrita. Tecer e escrever são realizações humanas que relacionam "a matéria e a ideia, a concepção ideal e o trabalho, a mão e a cabeça, o projeto e ação, a natureza e a cultura, a coisa e a palavra ${ }^{\text {LIII, }}$.

Nesse cenário, os folhetos de versos se apresentam como instrumentos de informação, entretenimento e cultura. Os poetas relatam as mudanças nos modos de vida, nos costumes e nas sensibilidades das pessoas. Eles tratam de assuntos que alimentam afirmativas, influenciam, convencem, confundem, confrontam, desiludem e divertem seus leitores/ouvintes. Assim, a arte de versejar pode ser entendida como uma produção que remete a certas realidades, ficções e subjetividades.

Constatamos que literatura de cordel do Nordeste é um conceito que foi fixado no universo de um discurso que tem por objetivo estereotipar a produção de folhetos rimados no Brasil, de maneira tradicional, mercadológica e até mesmo pejorativa.

Em suma, o objetivo aqui nesse texto foi promover mediações entre História, Literatura e Arte de Versejar. Temos convicção que este artigo não é um ponto final em si mesmo e nem esgota as discussões acerca dessa temática, porém se ele conseguir abrir espaços para novas problematizações e reflexões, ele terá cumprido o seu papel.

\section{Notas}

\footnotetext{
${ }^{\text {I }}$ Esse artigo apresenta-se como produto de uma pesquisa de Mestrado finalizada, denominada FRAGMENTOS DE HISTÓRIA EM VERSOS: Literatura de Folhetos na Primeira República (1889-1929), financiada por uma bolsa CAPES.

II Mestre em História Social da Cultura Regional pelo Programa de Pós-Graduação em História da UFRPE. Especialista em Gestão da Educação. Graduado em História. Integrante do Grupo de Estudos em História Social e Cultural - GEHISC. Professor (EaD/UFRPE).

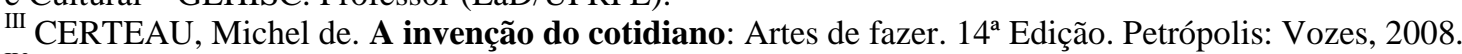

IV PESAVENTO, Sandra Jatahy. História e História Cultural. $3^{\text {a }}$ edição. Belo Horizonte: Autêntica, 2012, p. 107.

${ }^{\mathrm{V}}$ Idem. p. 108.

VI LUCIANO, Aderaldo. Apontamentos para uma história crítica do cordel brasileiro. São Paulo: Editora Luzeiro, 2012, p. 57.

VII GALVÃO, Ana Maria de Oliveira. Cordel: Leitores e ouvintes. Belo Horizonte: Autêntica, 2006. p. 193-194.

VIII LUCIANO, Aderaldo. Op. cit. p. 17-28.

IX Idem. p. 8-9.

Idem. p. 43

${ }^{\mathrm{XI}}$ LUCENA, Bruna Paiva de. Espaços em disputa: o cordel e o campo literário brasileiro. Brasília: Dissertação de Mestrado em Literatura e Práticas Sociais, Universidade de Brasília - UNB, 2010,p. 28.

XII Idem. p. 19.

XIII Idem. p. 42.

XIV Idem. p. 13.

$\mathrm{XV}$ Idem.

${ }^{X V I}$ Idem. p. 37.

XVII Idem. p. 32.

XVIII Idem. p. 26-27.

XIX Idem. p. 27-28.

${ }^{\mathrm{XX}}$ Idem. p. 41.

XXI JÚNIOR, Durval Muniz de Albuquerque. A Feira dos Mitos: a fabricação do folclore e da cultura popular (Nordeste 1920 - 1950). São Paulo: Intermeios, 2013, p. 27-32.

XXII Idem. p. 223.
} 
XXIII FERREIRA, Antonio Celso. A Fonte Fecunda. In: PINSKY, Carla Bassanezi; DE LUCA, Tania Regina (orgs.). O historiador e suas fontes. São Paulo: Editora Contexto, 2009. p.61-91.

XXIV Idem.

XXv GALVÃO, Ana Maria de Oliveira. Op. cit. p. 90.

XXVI Idem. p. 90-91.

XXVII Idem. p.91.

XXVIII Idem.

XXIX PESAVENTO, Sandra Jatahy. História \& literatura: uma velha-nova história. História cultural do Brasil Dossiê coordenado por Sandra Jatahy Pesavento. In: Revista Nuevo Mundo Mundos Nuevos, Debates, 2006. Site: http://nuevomundo.revues.org/index1560.html - consultado em 08/10/2013.

XXX Idem.

XXXI Idem.

XXXII Idem.

XXXIII Folheto de autoria de João Ferreira de Lima (s/d). Ele nasceu, em São José do Egito (PE), sua obra mais conhecida é As palhaçadas de João Grilo (um personagem do imaginário popular). Ele escreveu sobre vários temas da poesia de versos rimados, privilegiando as discussões e as pelejas. Faleceu em Bezerros. Ver: Fundação Casa de Rui Barbosa - http://www.casaruibarbosa.gov.br/.

XXXIV MAYA, Ivone. O povo de papel: a sátira política na literatura de cordel. RJ: Garamond, 2012, p. 27.

${ }^{X X X V}$ FERREIRA, Antonio Celso. Op. cit.

XXXVI MAYA, Ivone. Op. cit.

XXXVII FERREIRA, Antonio Celso. Op. cit.

XXXVIII PESAVENTO, Sandra Jatahy. Op. cit.

XXXIX Idem.

${ }^{\mathrm{XL}}$ FERREIRA, Antonio Celso. Op. cit.

${ }^{X L I}$ Idem.

XLII PESAVENTO, Sandra Jatahy. Op. cit.

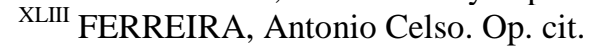

XLIV PESAVENTO, Sandra Jatahy. Op. cit.

${ }^{\mathrm{XLV}}$ FERREIRA, Antonio Celso. Op. cit.

XLVI Idem.

XLVII PESAVENTO, Sandra Jatahy. Op. cit.

XLVIII FERREIRA, Antonio Celso. Op. cit.

XLIX FERREIRA, Antonio Celso. Op. cit.

L JÚNIOR, Durval Muniz de Albuquerque. História: a arte de inventar o passado - Ensaios de teoria da história. São Paulo: EDUSC, 2007, p. 32.

LI Idem. 33.

LII Idem.

LIII Idem.

\section{REFERÊNCIAS}

ABREU, Márcia Azevedo de. Cordel Português/Folhetos Nordestinos: Confrontos - um estudo histórico-comparativo. $4^{\mathrm{a}}$ reimpressão. Campinas, SP: Mercado de Letras, 2011.

BATISTA, Sebastião Nunes. Antologia da Literatura de Cordel. $1^{\text {a }}$ Edição. Natal, Fundação José Augusto, 1977.

\section{2.}

. Poética popular do Nordeste. Rio de Janeiro: Fundação Casa de Rui Barbosa,

BENJAMIN, Walter. Magia e técnica, arte e política: ensaios sobre literatura e história da cultura (Obras Escolhidas - Volume 1). 8 ${ }^{a}$ Edição. São Paulo: Brasiliense, 2012.

BORGES, Vavy Pacheco. O que é História? 2a edição. São Paulo: Brasiliense, 2007. 
CANCLINI, Néstor García. Culturas Híbridas: estratégias para entrar e sair da modernidade. São Paulo: EDUSP, 1997.

CERTEAU, Michel de. A cultura no plural. 2a Edição. Campinas, São Paulo: Papirus, 1995.

A Escrita da História. 2a Edição. Rio de Janeiro: Forense Universitária, 2002.

A invenção do cotidiano: Artes de fazer. 14 Edição. Petrópolis: Vozes, 2008.

CHARTIER, Roger. A História Cultural: entre práticas e representações. Lisboa: DIFEL, 1990.

$\overline{11,1991 .}$

O mundo como representação. In: Estudos avançados. São Paulo: USP, vol. 5, nº

À Beira da Falésia: a História entre certezas e inquietudes. Porto Alegre: Editora da Universidade/UFRGS, 2002.

FERREIRA, Antonio Celso. A Fonte Fecunda. In: PINSKY, Carla Bassanezi; DE LUCA, Tania Regina (orgs.). O historiador e suas fontes. São Paulo: Editora Contexto, 2009.

GALVÃO, Ana Maria de Oliveira. Cordel: Leitores e ouvintes. Belo Horizonte: Autêntica, 2006.

GRILlO, Maria Ângela de Faria. A Arte do Povo: Histórias na Literatura de Cordel (19001940). Niterói, RJ: Tese de Doutorado - UFF, 2005.

JÚNIOR, Durval Muniz de Albuquerque. A Invenção do Nordeste e outras Artes. $2^{\mathrm{a}}$ Edição. São Paulo: Editora Cortez, 2009.

Edusc, 2007.

História: a arte de inventar o passado - Ensaios de teoria da história. São Paulo:

A Feira dos Mitos: a fabricação do folclore e da cultura popular (Nordeste 1920 1950). São Paulo: Intermeios, 2013.

KOSELLECK, Reinhart. Futuro Passado: contribuição à semântica dos tempos históricos. Rio de Janeiro: Contraponto: Editora PUC - Rio, 2006.

LUCENA, Bruna Paiva de. Espaços em disputa: o cordel e o campo literário brasileiro. Brasília: Dissertação de Mestrado em Literatura e Práticas Sociais, Universidade de Brasília UNB, 2010.

LUCIANO, Aderaldo. Apontamentos para uma história crítica do cordel brasileiro. São Paulo: Editora Luzeiro, 2012.

MAYA, Ivone. O povo de papel: a sátira política na literatura de cordel. Rio de Janeiro: Garamond, 2012. 
Ministério da Cultura. O cordel - Testemunha da História do Brasil. Literatura popular em verso, antologia/nova série - 2. Rio de Janeiro: Fundação Casa de Rui Barbosa, 1987.

PESAVENTO, Sandra Jatahy. História \& literatura: uma velha-nova história. História cultural do Brasil - Dossiê coordenado por Sandra Jatahy Pesavento. In: Revista Nuevo Mundo Mundos Nuevos, Debates, 2006. Site: http://nuevomundo.revues.org/index1560.html consultado em 08/10/2013.

Palavras para crer: Imaginários de sentido que falam do passado. História cultural do Brasil - Dossiê coordenado por Sandra Jatahy Pesavento. In: Revista Nuevo Mundo Mundos Nuevos, Debates, 2006. Site: http://nuevomundo.revues.org/1499 consultado em 30/07/2013.

História e História Cultural. $3^{a}$ edição. Belo Horizonte: Autêntica, 2012.

RICOEUR, Paul. A memória, a história, o esquecimento. Campinas, SP: Editora UNICAMP, 2007.

\section{SITES CONSULTADOS}

http://www.casaruibarbosa.gov.br - Fundação Casa de Rui Barbosa.

http://www.cnfcp.gov.br - Centro Nacional de Folclore e Cultura Popular.

http://www.portaldocordel.com.br/downloads.html - Portal do Cordel.

http://www.ablc.com.br/ - Academia Brasileira de Literatura de Cordel. 